\title{
Erratum to: Skeletal Muscle Depletion is Associated with Severe Postoperative Complications in Patients Undergoing Cytoreductive Surgery with Hyperthermic Intraperitoneal Chemotherapy for Peritoneal Carcinomatosis of Colorectal Cancer
}

Jeroen L. A. van Vugt, MD ${ }^{1}$, Hidde J. Braam, MD ${ }^{1}$, Thijs R. van Oudheusden, MD ${ }^{2}$, Asra Vestering, BSc ${ }^{1}$, Thomas L. Bollen, MD, $\mathrm{PhD}^{3}$, Marinus J. Wiezer, $\mathrm{MD}$, $\mathrm{PhD}^{\mathbf{1}}$, Ignace H. J. T. de Hingh, $\mathrm{MD}, \mathrm{PhD}^{2}$, Bert van Ramshorst, $\mathrm{MD}, \mathbf{P h D}^{\mathbf{1}}$, and Djamila Boerma, $\mathbf{M D}, \mathbf{P h D}^{\mathbf{1}}$

${ }^{1}$ Department of Surgery, St Antonius Hospital, Nieuwegein, The Netherlands; ${ }^{2}$ Department of Surgery, Catharina Hospital, Eindhoven, The Netherlands; ${ }^{3}$ Department of Radiology, St Antonius Hospital, Nieuwegein, The Netherlands

\section{ERRATUM TO: ANN SURG ONCOL DOI 10.1245/S10434-015-4429-Z}

In the original article there is an error in the Results section of the abstract. The corrected sentence is as follows:

The mean L3 muscle index was significantly lower for the patients who experienced severe postoperative complications than for the patients without severe postoperative complications ( 43.3 vs. $47.0 \mathrm{~cm}^{2} / \mathrm{m}^{2} ; \mathrm{p}=$ $0.005)$.
The same error occurred in the Results section on page 4, right column, of the original article. The corrected sentence is as follows:

The mean L3 muscle index was significantly lower for the patients who experienced severe postoperative complications (i.e., Clavien-Dindo classification $\geq 3$ ) than for the patients without severe postoperative complications (43.3 vs. $47.0 \mathrm{~cm}^{2} / \mathrm{m}^{2} ; \mathrm{p}=0.005$ ).

The online version of the original article can be found under doi:10.1245/s10434-015-4429-z.

(C) Society of Surgical Oncology 2015

Published Online: 20 March 2015

D. Boerma, $\mathrm{MD}, \mathrm{PhD}$

e-mail: d.boerma@antoniusziekenhuis.nl 